\title{
A survey on the treatment of atrial fibrillation in South Africa
}

R M Jardine, ${ }^{1}$ FCP (SA); J Fine, ${ }^{2}$ FCP (SA) Neurology, BMus (Musicology); I W P Obel, ${ }^{3}$ FCP (SA), FACC

${ }^{1}$ Linmed Hospital, Benoni, Gauteng, South Africa

${ }^{2}$ Sanofi, Midrand, Gauteng, South Africa

${ }^{3}$ Milpark Hospital, Johannesburg, South Africa

Corresponding author: R M Jardine (jardinerm@gmail.com)

Background. The burden of cardiovascular disease is expected to escalate in developing countries. However, studies and guidelines concerning atrial fibrillation $(\mathrm{AF})$ are restricted to the developed world.

Objectives. To assess the treatment modalities of AF in South Africa.

Methods. A cross-sectional, observational, multicentre, national registry of the treatment of 302 patients with AF was conducted from February 2010 to March 2011. Specific drug use for rate or rhythm control, as well as drug use for stroke prevention, was surveyed. Events during the 12 months prior to the survey were also characterised, including non-drug treatments, resource utilisation and complications. Results. The single most prevalent clinical characteristic was hypertension (65.9\%). Rhythm control was being pursued in 109 patients (36.1\%) with class Ic and class III antiarrhythmic agents, while rate control, mainly with beta-blockers, was pursued in the remainder of the patients. Concomitant use of other cardiovascular drugs was high, and $75.2 \%$ of patients were on warfarin for stroke prevention. There was a high burden of AF-related morbidity during the preceding year, with 32.5\% reporting a history of heart failure, $8.3 \%$ a stroke and $5.3 \%$ a transient ischaemic attack. Therapeutic success, as defined by either the presence of sinus rhythm or rate-controlled AF, was achieved in $86.8 \%$ as judged clinically by the treating physician, but in only $70.2 \%$ according to the electrocardiogram criterion of heart rate $\leq 80 \mathrm{bpm}$. Conclusion. There were no striking differences from previously reported registries worldwide. The lack of application of strict rate control criteria is highlighted.

S Afr Med J 2014;104(9):623-627. DOI:10.7196/SAMJ.8111 


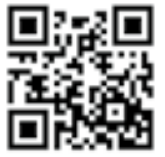

Atrial fibrillation (AF) is the most common cardiac arrhythmia, with a prevalence of $5-6 \%$ in the 65 -year-old population, increasing up to $10 \%$ in the $>80$ years population. ${ }^{[1-4]}$

Despite the improvement in primary and secondary prevention of predisposing underlying cardiac conditions such as ischaemic heart disease and hypertension, the prevalence of AF continues to rise in developed countries due to ageing and increasing obesity of the population. ${ }^{[3,5,6]}$ The treatment of AF is undergoing significant revision throughout the world and in a number of ways, especially with regard to stroke prevention, ablation for rhythm control, and novel antiarrhythmic drugs. This has triggered a number of guidelines ${ }^{[7,8]}$ and guideline updates, ${ }^{[9,10]}$ as well as a number of registries and surveys on $\mathrm{AF}$ and $\mathrm{AF}$ management in various parts of the world (e.g. Nieuwlaat et al. ${ }^{[11]}$ and Camm et al. ${ }^{[12]}$ ). In South Africa (SA), the prevalence of AF in the urban black population has recently been documented to be $7 \%$ in a cardiovascular disease cohort ( $8 \%$ of heart failure patients, $4 \%$ of hypertensive patients, and $13 \%$ of valvular disease patients). ${ }^{[13]}$ However, very little has been published on AF management outside the developed world. This prompted the Assessment of the Therapeutic Management of Patients with Atrial Fibrillation in South Africa (SAFIR-RSA). The principal objective of the study was to assess the baseline characteristics of patients with AF and the treatment modalities utilised, particularly the use of rate and rhythm control strategies. The study also looked at hospitalisation rates and prevention of thromboembolism.

\section{Methods}

SAFIR-RSA was a prospective cross-sectional, non-interventional, observational disease registry carried out in 29 medical institutions spanning nine urban centres in SA. Patients were largely drawn from the private insured medical sector and therefore represent a relatively affluent stratum of the population.

\section{Patients}

The study protocol was approved by an independent ethics committee, and written informed consent was obtained from patients before study entry in accordance with Helsinki (1964) ethical recommendations. Adult patients ( $\geq 21$ years) with electrographically documented AF were enrolled in the registry. Patients were excluded if they had developed AF within 3 months of cardiac surgery, had acute AF apparently precipitated by non-cardiac conditions (e.g. pneumonia), or had recently participated in an AF trial.

\section{Procedure}

A medical history taken at enrolment included recording each patient's treatment, the clinical presentation of $\mathrm{AF}$, the presence or absence of comorbidities, and all data pertaining to the primary and secondary outcomes (see below). The physicians or cardiologists in each participating medical centre completed a standardised 6-page case report form for every enrolled patient.

\section{Primary evaluation criteria}

These included: $(i)$ the prevalence of AF treatment modalities, namely the proportion of patients receiving rhythm control agents (class I and III) and/or rate control agents (class II and IV, and cardiac glycosides), cardioversion, ablation or other procedures; and (ii) the use of treatments to prevent thromboembolism, namely the proportion of patients taking vitamin $\mathrm{K}$ antagonists, acetylsalicylic acid or other antiplatelet agents. Any other cardiovascular treatments were also noted.

\section{Secondary evaluation criteria}

These included: (i) the proportion of patients with controlled AF, defined as either in sinus rhythm (SR) (recorded during the visit) or at heart rate control target ( $\leq 80 \mathrm{bpm}$ at rest); and (ii) the incidence of clinical outcomes in the year preceding the inclusion, defined as hospitalisations for AF and other related cardiovascular events such as stroke, transient ischaemic attack, heart failure and myocardial ischaemia.

\section{Statistical analysis}

The data from all the participating medical centres were combined and treated as one dataset for the purposes of the analysis. Data analysis was performed with SAS statistical software, Release 9.2 (SAS Institute, USA). Continuous variables are reported as mean (standard deviation (SD)) and non-continuous variables as number/percentage of patients. The statistical analysis was mainly of a descriptive nature, and sub-analyses were not prespecified in the protocol. Post-hoc subanalyses were performed using Fisher's exact test. A $p$-value of $<0.05$ was considered statistically significant.

\section{Results}

The study population consisted of 302 AF patients (59.9\% male) from 29 centres, enrolled from 18 February 2010 to 9 March 2011. The mean age was 67 (SD 13) years (range 21 - 95). The mean waist circumference was 101.6 (SD 17.8) $\mathrm{cm}$ and the mean body mass index $\left(\mathrm{kg} / \mathrm{m}^{2}\right) 28.8$ (SD 5.9), indicating a high prevalence of overweight patients in the cohort.

\section{Clinical characteristics}

The single most prevalent clinical characteristic was hypertension (65.9\%). Other coronary risk factors were also frequent (dyslipidaemia $48.3 \%$ and diabetes $15.6 \%$ ). Concomitant structural heart disease was common, with $27.5 \%$ having valvular disease (of whom $79.5 \%$ had mitral valve disease), $26.8 \%$ coronary artery disease, and $32.5 \%$ heart failure; $28.5 \%$ of these patients had New York Heart Association class III or IV symptoms. In keeping with these comorbidities, $27.5 \%$ of patients had a history of previous cardiac or vascular interventions. Non-cardiac comorbidities were not common, comprising thyroid disease in $14.2 \%$ (3.3\% hyperthyroid and $10.9 \%$ hypothyroid) and renal disease in $10.9 \%$ (Table 1 ).

The time course of AF was paroxysmal in $32.1 \%$ of patients, persistent in $21.2 \%$ and permanent in $46.7 \%$. During the preceding 12 months, $40.7 \%$ of patients had experienced symptoms of AF.

\section{Pharmacological treatment}

The drug therapy at the time of the survey visit is listed in Table 2. For the purposes of this analysis, 'rhythm control' was defined as the chronic use of class Ic or class III drugs for the maintenance of SR, and all others were deemed 'rate control'. Rhythm control was being pursued in 109 patients (36.1\%) with class Ic and class III agents, while rate control was pursued in the remainder (63.9\%). Amiodarone accounted for $79.4 \%$ of class III drugs used. A number of patients in the rhythm control group were receiving rate control medications in addition, but this number is not extractable from the data. Beta-blockers were the most frequently used rate control drugs. Combinations of beta-blockers, digoxin and rate-controlling calcium channel blockers were often employed. Concomitant use of other cardiovascular drugs was high, especially diuretics (53.0\%), statins (44.0\%), angiotensin-converting enzyme inhibitors (39.1\%) and angiotensin receptor blockers (22.5\%). For stroke prevention, $75.2 \%$ were on warfarin, $39.4 \%$ on aspirin and $5.0 \%$ on clopidogrel. 
Table 1. Clinical characteristics

\begin{tabular}{|c|c|c|}
\hline & $\begin{array}{l}\text { History of } \\
\text { condition } \\
n(\%)\end{array}$ & $\begin{array}{l}\text { Treated for condition in } \\
\text { preceding } 12 \text { months } \\
n \text { (\% of those with condition) }\end{array}$ \\
\hline \multicolumn{3}{|l|}{ Cardiac risk factors $(N=302)$} \\
\hline \multicolumn{3}{|l|}{ Smoking } \\
\hline Current & $27(9.0)$ & \\
\hline Former & $123(40.7)$ & \\
\hline Never & $142(47.0)$ & \\
\hline Hypertension & $199(65.9)$ & $198(99.5)$ \\
\hline Diabetes $^{\star}$ & $47(15.6)$ & $44(93.6)$ \\
\hline Dyslipidaemia & $146(48.3)$ & $127(87.0)$ \\
\hline \multicolumn{3}{|l|}{ Cardiac comorbidities $(N=302)$} \\
\hline Coronary artery disease & $81(26.8)$ & $23(28.4)$ \\
\hline Myocardial infarction & $34(11.3)$ & $4(11.8)$ \\
\hline Peripheral arterial disease & $9(3.0)$ & $1(11.1)$ \\
\hline Carotid stenosis & $3(1.0)$ & \\
\hline Valvular heart disease & $83(27.5)$ & $9(10.8)$ \\
\hline Arrhythmia other than $\mathrm{AF}^{\dagger}$ & $42(13.9)$ & $11(26.2)$ \\
\hline Total & $83(27.5)$ & $20(24.1)$ \\
\hline \multicolumn{3}{|c|}{ Cardiac and vascular interventions $(N=83)$} \\
\hline PCI & $23(27.7)$ & \\
\hline CABG & $16(19.3)$ & \\
\hline Carotid intervention & $1(1.2)$ & \\
\hline Valvular surgery & $25(30.1)$ & \\
\hline CABG + valvular surgery & $3(3.6)$ & \\
\hline $\mathrm{PCI}+\mathrm{CABG}$ & $4(4.8)$ & \\
\hline PCI + valvular surgery & $1(1.2)$ & \\
\hline PCI + carotid intervention & $1(1.2)$ & \\
\hline Unknown & $9(10.9)$ & \\
\hline \multicolumn{3}{|c|}{ Non-cardiac comorbidities $(N=302)$} \\
\hline Thyroid disease & $43(14.2)$ & \\
\hline Renal disease & $33(10.9)$ & \\
\hline \multicolumn{3}{|c|}{$\begin{array}{l}\mathrm{AF}=\text { atrial fibrillation: } \mathrm{PCI}=\text { percutaneous coronary intervention; } \mathrm{CABG}=\text { coronary artery bypass graft. } \\
\begin{array}{r}{ }^{9} 77.9 \% \text { had type } 2 \text { diabetes. } \\
600.4 \% \text { had atrial flutter. }\end{array}\end{array}$} \\
\hline
\end{tabular}

\section{Events and hospitalisations in the preceding 12 months}

Treatments for AF in the preceding 12 months included pharmacological cardioversion (17.5\%), electrical cardioversion (13.2\%), catheter ablation (4.2\%) and pacemaker implantation (5.3\%). Interestingly, a number of patients had an unusually large number of cardioversions in the previous year: 6 patients had two attempts at electrical cardioversion, 2 underwent three attempts, and a further 2 underwent four attempts. One patient had six pharmacological cardioversion attempts.

Of the total cohort, 104 patients (34.4\%) had required hospitalisation during the previous 12 months, with a third of these patients requiring multiple hospitalisations. AF-related morbidity requiring hospitalisation was particularly frequent for heart failure (11.6\% of study patients, 35/98 with heart failure), and for stroke, transient ischaemic attack and peripheral embolism (3.9\% of study patients, $12 / 58$ with these conditions) (Table 3). Haemorrhage occurred in 23 patients $(7.6 \%)$ during the preceding year, but was considered to be serious enough to warrant hospitalisation in only 8 cases. One patient had intracranial haemorrhage. The mean duration of hospital stay was 5.2 days. The average number of outpatient consultations for AF or other cardiovascular reasons in the preceding year was 1.74 .

\section{Control of AF}

The rhythm status of patients at the time of the survey is shown in Table 4. Only 85 patients ( $28.1 \%$ of the total study cohort) were in SR; notably, 31 of these were on rate control medications alone. Of the patients in $\mathrm{AF}$ at the time of the survey, $81.5 \%$ were judged in the opinion of the enrolling investigator to be satisfactorily rate controlled. However, when utilising a strict electrocardiogram (ECG) criterion of rate $\leq 80 \mathrm{bpm}$, only $58.4 \%$ of patients in AF would fulfil this definition. Using the 'lenient' rate control criterion of $\leq 110 \mathrm{bpm}$ proposed by the RACE II trial, ${ }^{[8]}$ $90.6 \%$ of patients would fulfil this definition. 'Therapeutic success' as defined by either the presence of SR or rate-controlled $\mathrm{AF}$ was achieved in $86.8 \%$ of the total population on the basis of the clinicians' clinical judgement, but only in $70.2 \%$ as judged by the EGC criterion of rate $\leq 80 \mathrm{bpm}$.

A post-hoc sub-analysis was performed to compare the strategies of rhythm control with rate control (Table 5). Patients prescribed rhythm control medications were somewhat younger, had more medication changes in the preceding year, had more hospitalisations for AF or cardiovascular reasons, and underwent pharmacological and electrical cardioversion more frequently than the rate control group. The rhythm control group had significantly more hospitalisations for coronary artery disease (50.0\% v. $16.3 \%)$, myocardial infarction (28.6 v. $0 \%)$ and heart failure $(57.6 \%$ v. $25.8 \%)$.

\section{Prevention of thromboembolic complications}

The mean $\mathrm{CHA}_{2} \mathrm{DS}_{2}$-VASc score (congestive heart failure or left ventricular dysfunction, hypertension, age $\geq 75$ ( 2 points), diabetes, stroke (2 points), vascular disease, age 65 - 74, sex category) for the entire cohort of patients was 3.08 , and there was no significant difference in scores of patients on warfarin $v$. those not on warfarin (3.12 v. 2.96, respectively). Of patients not using vitamin $\mathrm{K}$ antagonists, $78.6 \%$ had $\mathrm{CHA}_{2} \mathrm{DS}_{2}-$ VASc scores $\geq 2$.

There was a poor correlation between the actual $\mathrm{CHA}_{2} \mathrm{DS}_{2}$-VASc score and use of anticoagulation, as follows: score of 0 (65\%); score of $1(83 \%)$; score of $2(68 \%)$; score of 3 (76\%); score of 4 (79\%); score of 5 (76\%); score of $6(81 \%)$; score of $7(25 \%$, $1 / 4$ patients); score of 8 (100\%, $4 / 4$ patients).

\section{Discussion}

The primary outcome measure in the SAFIRRSA survey was to evaluate the incidence of $\mathrm{AF}$ treatment modalities and thromboembolic prevention treatments in a cross-sectional 


\begin{tabular}{|c|c|}
\hline Medication & $n(\%)$ \\
\hline Cardiovascular & $109^{\star}(36.1)$ \\
\hline \multicolumn{2}{|l|}{ Rhythm control agents } \\
\hline Ic & $9(3.0)$ \\
\hline III & $102(33.8)$ \\
\hline \multicolumn{2}{|l|}{ Rate control agents } \\
\hline Beta-blockers (excluding sotalol) & $180(59.6)$ \\
\hline HR-lowering CCBs & $40(13.2)$ \\
\hline Cardiac glycosides & $76(25.2)$ \\
\hline \multicolumn{2}{|l|}{ Other } \\
\hline Beta-blockers (not prescribed for AF) & $44(14.6)$ \\
\hline Diuretics & $160(53.0)$ \\
\hline Dihydropyridine CCBs & $43(14.2)$ \\
\hline ACE inhibitors & $118(39.1)$ \\
\hline Angiotensin II receptor antagonist & $68(22.5)$ \\
\hline Vasodilators & $10(3.3)$ \\
\hline Other antihypertensives & $19(6.3)$ \\
\hline Statins & $133(44.0)$ \\
\hline Other lipid-lowering agents & $7(2.3)$ \\
\hline Oral antidiabetic agents & $45(14.9)$ \\
\hline Insulin & $13(4.3)$ \\
\hline \multicolumn{2}{|l|}{ Antithrombotic } \\
\hline Vitamin $\mathrm{K}$ antagonist & $227(75.2)$ \\
\hline Acetylsalicylic acid & $119(39.4)$ \\
\hline Clopidogrel & $15(5.0)$ \\
\hline Other antiplatelet/anticoagulant agents & $5(1.7)$ \\
\hline INR in past 6 months & $218(96.0)^{\dagger}$ \\
\hline \multicolumn{2}{|c|}{$\begin{array}{l}\mathrm{HR}=\text { heart rate; } \mathrm{CCBs}=\text { calcium channel blockers; } \mathrm{AF}=\text { atrial fibrillation; } \\
\mathrm{ACE}=\text { = angiotensin-converting enzyme, } \mathrm{INR}=\text { international normalised ratio. } \\
\text { *Two patients were on both class Ic and class III agents. } \\
\text { 'T5 missing values. }\end{array}$} \\
\hline
\end{tabular}

representative cohort of patients with AF in SA. The results clearly showed that the majority of patients were receiving rate control therapy (63.9\%), usually in the form of beta-blockers, either alone or in combination with other rate control agents. Rhythm control therapy for the remainder of the patients consisted primarily of class III agents. Concomitant use of other cardiovascular drugs was high in both treatment strategies. Since the patient cohort included the elderly, with a high frequency of other cardiac risk factors and structural heart disease, it is not surprising that the majority were being treated with a rate control strategy. According to European Society of Cardiology guidelines, rate control is a reasonable strategy in elderly patients in whom the level of symptoms related to $\mathrm{AF}$ is deemed acceptable. ${ }^{[8]}$ Nevertheless, the findings do suggest that clinicians in SA apply lenient rate control criteria and judge patients to be rate controlled with a resting pulse rate of less than $110 \mathrm{bpm}$.

There were no striking differences in the baseline clinical characteristics of this study population when compared with other worldwide registries. Notably, the prevalence of underlying comorbidities such as coronary artery disease, valvular disease and heart failure in the present study is similar ( $20-30 \%$ for each) to those reported in the developed world. ${ }^{[8]}$ This is perhaps not surprising because, although the aim of this study was to focus for the first time on SA patients, the cohort was largely
Table 3. AF morbidity in preceding 12 months

\begin{tabular}{|c|c|c|}
\hline Diagnosis & $\begin{array}{l}\text { History of } \\
\text { condition } \\
n / N(\%)\end{array}$ & $\begin{array}{l}\text { Hospitalised in } \\
\text { preceding } 12 \\
\text { months } \\
n \text { (\% of those with } \\
\text { condition) }\end{array}$ \\
\hline Heart failure $(N=302)$ & $98(32.5)$ & $35(35.7)$ \\
\hline \multicolumn{3}{|l|}{ NYHA class } \\
\hline I & $22 / 98(22.5)$ & \\
\hline II & $48 / 98(49.0)$ & \\
\hline III & 26/98 (26.5) & \\
\hline IV & $2 / 98(2.0)$ & \\
\hline $\begin{array}{l}\text { LVEF }(\%) \text { in preceding } \\
12 \text { months }(N=302)\end{array}$ & $243(80.4)$ & \\
\hline$<30$ & $7 / 243(2.9)$ & \\
\hline $30-40$ & $26 / 243(10.7)$ & \\
\hline $41-50$ & $33 / 243(13.6)$ & \\
\hline$>50$ & $177 / 243(72.8)$ & \\
\hline Stroke $(N=302)$ & $36(11.9)$ & $3(8.3)$ \\
\hline TIA $(N=302)$ & $16(5.3)$ & $7(43.8)$ \\
\hline $\begin{array}{l}\text { Peripheral embolic } \\
\text { events }(N=302)\end{array}$ & $6(2.0)$ & $2(33.3)$ \\
\hline $\begin{array}{l}\mathrm{AF}=\text { atrial fibrillation; } \\
\text { ejection fraction; } ; \mathrm{TIA}=\text { =transien }\end{array}$ & $\begin{array}{l}\text { v York Heart Associat } \\
\text { haemic attack. }\end{array}$ & ; LVEF = left ventricular \\
\hline
\end{tabular}

derived $(88.7 \%)$ from insured patients, a more affluent sector of the population that would more closely approximate a First-World setting. The racial groups of the subjects, frequently used as a proxy for socioeconomic status, are unknown.

The primary outcome measure of the SAFIR-RSA survey also included an assessment of the use of thromboembolic prevention treatments. The novel oral anticoagulants were not yet in use at the time of the survey. The findings show that the large majority of patients $(75.2 \%)$ were receiving warfarin for stroke prevention. There were, however, a significant number of patients not receiving anticoagulation who, with $\mathrm{CHA}_{2} \mathrm{DS}_{2}$-VASc scores $\geq 2$, should have had thromboembolic prevention therapy according to current treatment guidelines. ${ }^{[10]}$ Nearly all the patients on warfarin had had international normalised ratio monitoring during the previous 6 months. This diligent monitoring may account for the low rate of hospitalisation for haemorrhage of only $2.6 \%$ (8 patients) during the preceding year, compared with rates of $6.8-7.2 \%$ reported in other observational studies on older patients with $\mathrm{AF}$ receiving warfarin. ${ }^{[14]}$

In the present survey, hospitalisations for coronary artery disease, myocardial infarction and heart failure occurred more frequently in the group on antiarrhythmic agents. It is not clear whether these developments are a result of antiarrhythmic drug therapy, or whether rhythm control is preferred as a strategy in patients with these conditions.

\section{Study limitations}

There are a number of limitations to this study. The patient sample does not necessarily reflect the true cross-sectional population of AF patients in SA, as most had medical insurance coverage. Site selection bias is likely, with over-representation of cardiologists with specialisation or particular interest in AF. Case selection bias may also have been introduced because it was not mandated that consecutive cases be included at each site. Investigator knowledge of the sponsor 
Table 4. Current control at time of the survey

\begin{tabular}{lll}
\hline & $n(\%)$ & Total patients, $N$ \\
\hline In SR at visit & $85(28.1)$ & 302 \\
In AF at visit & $217(71.9)$ & \\
$\quad$ Symptomatic & $68(22.5)$ & \\
In AF but rate controlled & & \\
$\quad$ Investigator opinion & $177(81.5)$ & 217 \\
$\quad$ ECG criterion, HR $\leq 80$ bpm & $125(58.4)$ & $214^{*}$ \\
$\quad$ ECG criterion, HR $\leq 110$ bpm & $194(90.6)$ & $214^{*}$ \\
$\begin{array}{l}\text { Therapeutic success (in SR or in AF with rate } \\
\text { controlled) }\end{array}$ & \\
$\quad$ Investigator opinion & $262(86.8)$ & 302 \\
$\quad$ ECG criteria & $210(70.2)$ & $299^{*}$ \\
$\begin{array}{l}\text { SR }=\text { sinus rhythm; AF = atrial fibrillation; ECG = electrocardiogram; HR = heart rate. } \\
\text { *3 patients in AF did not have ECGs. }\end{array}$ &
\end{tabular}

Table 5. Sub-analysis of rate control v. rhythm control strategies

\begin{tabular}{|c|c|c|c|}
\hline & $\begin{array}{l}\text { Rate control } \\
(N=193)\end{array}$ & $\begin{array}{l}\text { Rhythm control } \\
(N=109)\end{array}$ & $p$-value ${ }^{*}$ \\
\hline Age (years) & 68.3 & 65.3 & 0.05 \\
\hline Pharmacological cardioversion, $n(\%)$ & $6(3.2)$ & $47(43.9)$ & $<0.001$ \\
\hline Electrical cardioversion, $n(\%)$ & $16(8.4)$ & $24(22.2)$ & 0.001 \\
\hline AF at visit, $n(\%)$ & $162(83.9)$ & $55(50.5)$ & $<0.001$ \\
\hline Rate control, $n(\%)$ & $141(88.1)$ & $36(65.4)$ & $<0.001$ \\
\hline $\begin{array}{l}\text { Hospitalisation for } \mathrm{AF} \text { or } \mathrm{CV} \text { reasons, } \\
n(\%)^{\dagger}\end{array}$ & $49(25.4)$ & $55(50.5)$ & $<0.001$ \\
\hline History of CVD, $n(\%)$ & $51(27.0)$ & $30(27.8)$ & 0.892 \\
\hline Hospitalisation for CVD, $n / N(\%)^{\dagger}$ & $8 / 49(16.3)$ & $15 / 30(50.0)$ & 0.002 \\
\hline History of MI, $n(\%)$ & $20(10.5)$ & $14(13.0)$ & 0.57 \\
\hline Hospitalisation for MI, $n / N(\%)^{\dagger}$ & $0(0)$ & $4 / 14(28.6)$ & 0.022 \\
\hline History of CHF, $n(\%)$ & $64(33.3)$ & $34(31.2)$ & 0.789 \\
\hline Hospitalisation for CHF, $n(\%)^{\dagger}$ & $16 / 62(25.8)$ & 19/33 (57.6) & 0.004 \\
\hline
\end{tabular}

may have introduced an additional bias in favour of patients on amiodarone.

\section{Conclusions}

The data in the SAFIR-RSA survey conform to similar registries in the developed world. Despite the focus on a relatively affluent sub-sector of the SA population, resulting in a near duplication of studies carried out in other developed countries, this is the first epidemiological study generating data on management of AF in SA. AF is a significant burden in cardiology practice in this country, with considerable resource utilisation and morbidity for patients. This survey highlights a lack of rigour in applying definitions of rate control and under-utilisation of antithrombotic therapy. Although only a 'snapshot', clinicians should be aware of these findings and attempt to improve drug utilisation and patient outcomes.

Acknowledgements. This survey was sponsored by Sanofi, Midrand, Gauteng, SA. Prof. Herman Schoeman of Clinstat CC, Pretoria, SA, performed the statistical analyses. Mrs Catherine Jardine provided secretarial assistance. The following physicians and cardiologists are acknowledged for their participation: M Alison, L Bushidi, G A Cassel, C Corbett, A J Dalby, G C Ellis, C P Franklin, D J Gilmer, T J Gray, M Heradien, J King, R D V Lamparelli, G Letcher, L Lombard, H Louw, E
Maree, J McKibbin, R Moodley, I W P Obel, A Okreglicki, A Roodt, F A Snyders, R Spammer, A Stanley, S N Thackersee, H Theron, $\mathrm{N}$ van der Merwe, P D Whitfield, R Zeelie.

Conflict of interest. RMJ reports receipt of a contractual fee from Sanofi-Aventis as Principal Investigator, and also lecture fees and travel expenses from Aspen Pharmaceuticals, Bayer Healthcare, Boehringer-Ingelheim, BristolMyers Squibb, Cipla-Medpro, Medtronic and Sanofi-Aventis. JF is a medical advisor at Sanofi. IWPO is a consultant and investigator for Medtronic and has received lecture fees and travel expenses from Medtronic, BoehringerIngelheim and Bayer Healthcare.

\section{References}

1. Greenlee RT, Vidaillet H. Recent progress in the epidemiology of atrial fibrillation. Curr Opin Cardiol 2005;20(1):7-14

2. Furberg CD, Psaty BM, Manolio TA, Gardin JM, Smith VE, Rautaharju PM. Prevalence of atrial fibrillation in elderly subjects Rautaharju PM. Prevalence of atrial fibrillation in elderly subjects
(the Cardiovascular Health Study). Am J Cardiol 1994;74(3):236(the Cardiovascular Health Study). Am J Cardiol 1994;

241. [http://dx.doi.org/10.1016/0002-9149(94)90363-8] RG. Prevalence, age distribution, and gender of patients with atrial fibrillation: Analysis and implications. Arch Intern Med 1995;155(5):469-473. [http://dx.doi.org/10.1001/ archinte.155.5.469]

4. Wattigney WA, Mensah GA, Croft JB. Increased atrial fibrillation mortality: United States, 1980-1998. Am J Epidemiol 2002;155(9):819-826. [http://dx.doi.org/10.1093/aje/155.9.819]

5. Go AS, Hylek EM, Phillips KA, et al. Prevalence of diagnosed atrial fibrillation in adults: National implications of for rhythm management and stroke prevention: The Anticoagulation management and stroke prevention: The Anticoagulation and Risk Factors in Atrial Fibrillation (ATRIA) study. JAMA 2001;285(18):2370-2375. [http://dx.doi.org/10.1001/
jama.285.18.2370]

Ryder KM, Benjamin EJ. Epidemiology and significance of atrial fibrillation. Am J Cardiol 1999;84(9A):131R-138R. [http://dx.doi. org/10.1016/S0002-9149(99)00713-4]

7. Fuster V, Ryden LE, Cannom DS, et al. ACC/AHA/ESC 2006 guidelines for the management of patients with atrial fibrillation: A report of the American College of Cardiology/American Heart Association Task Force on Practice Guidelines and the European Society of Cardiology Committee for Practice Guidelines: Developed in collaboration with the European Heart Rhythm Association and the Heart Rhythm Society. Executive summary. Eur Heart J 2006;27(16):1979-2030. [http://dx.doi.org/ 10.1093/ eurheartj/ehl176]

8. Camm AJ, Kirchhof P, Lip GY, et al. Guidelines for the management of atrial fbrilhtion: The Tak Force for the Managment of $\mathrm{Ar}$ of atrial fibill Fibrillation of the European Society of Cardiology. Eur Heart ]
2010;31(19):2369-2429. [http://dx.doi.org/ 10.1093/eurheartj/ ehq278]

9. Wann LS, Curtis AB, January CT, et al. 2011 ACCF/AHA/HRS

9. Wann LS, Curtis AB, January CT, et al. 2011 ACCF/AHA/HRS
focused update on the management of patients with atrial fibrillation (updating the 2006 guideline). Heart Rhythm 2011;8(1):157-176. [http://dx.doi.org//110.1016/j.hrthm.2010.11.047]

10. Camm AJ, Lip GYH, De Caterina R, et al. 2012 focused update of the ESC Guidelines for the management of atrial fibrillation. Eur Heart J 2012;33(21):2719-2747. [http://dx.doi.org/10.1093/ eurheartj/ehs253]

11. Nieuwlaat R, Capucci A, Camm AJ, et al. Atrial fibrillation management: A prospective survey in ESC member countries - the Euro Heart Survey on Atrial Fibrillation. Eur Heart I - the Euro Heart Survey on Atrial Fibrillation. Eur Heart
2005;26(22):2422-2434. [http://dx.doi.org/10.1093/eurheartj/ ehi505]

12. Camm AJ, Breithardt G, Crijns H, et al. Real life observations of clinical outcomes with rhythm- and rate control therapies for atrial fibrillation - RECORDAF (Registry on Cardiac Rhythm Disorders Assessing the Control of Atrial Fibrillation). J Am Coll Cardiol 2011;58(5):493-501. [http://dx.doi.org/10.1016/j.jacc.2011.03.03]

13. Sliwa K, Carrington MJ, Klug E, et al. Predisposing factors and incidence of newly diagnosed atrial fibrillation in an urban African community: Insights from the Heart of Soweto Study. Heart 2010;96(23):1878-1882. [http://dx.doi.org/10.1136/ hrt.2010.206938]

14. Gomes T, Mamdani MM, Holbrook AM, Paterson JM, Hellings C, Juurlink DN. Rates of haemorrhage during warfarin therapy for atrial fibrillation. CMAJ 2013;185(2):E121-E127. [http://dx doi. org/10.1503/cmaj.121218

Accepted 20 June 2014 